\title{
Moral Emotions and Ethics in Organisations: Introduction to the Special Issue
}

\author{
Dirk Lindebaum $^{1} \cdot$ Deanna Geddes $^{2} \cdot$ Yiannis Gabriel $^{3}$
}

Received: 26 April 2016/ Accepted: 4 May 2016/Published online: 20 May 2016

(C) Springer Science+Business Media Dordrecht 2016

\begin{abstract}
The aim of our special issue is to deepen our understanding of the role moral emotions play in organisations as part of a wider discourse on organisational ethics and morality. Unethical workplace behaviours can have far-reaching consequences-job losses, risks to life and health, psychological damage to individuals and groups, social injustice and exploitation and even environmental devastation. Consequently, determining how and why ethical transgressions occur with surprising regularity, despite the inhibiting influence of moral emotions, has considerable theoretical and practical significance to management scholars and managers alike. In this introduction, we present some of the core arguments in the field; notably, the effect of organisational life and bureaucracy on emotions, in general, and moral emotions, in particular; the moral standing of leaders, managers and followers; moral challenges raised by obedience and resistance to
\end{abstract}

Dirk Lindebaum

mail@dirklindebaum.eu

http://www.dirklindebaum.eu

1 Cardiff Business School, Cardiff, UK

2 Fox Business School, Temple University, Philadelphia, USA

3 School of Management, University of Bath, Bath, UK organisational power and ethical blindspots induced by what may appear as deeply moral emotions. These issues are explored by a collection of geographically diverse articles in various work contexts, which are thematically organised in terms of (i) moral emotions, ethical behaviour and social pressure, (ii) moral emotions and their consequences within/across levels of analysis, (iii) psychoanalytic perspectives on the management of moral emotions, (iv) virtue and moral emotions and (v) moral emotions and action tendencies. We end by suggesting certain avenues for future research in the hope that the endeavour initiated here will inspire improved practice at work.

Keywords Ethics - Moral emotions - Morality organisation · Organising · Unethical behaviour

\section{Introduction}

Do moral emotions and ethical behaviour matter in today's organisations? If we subscribe to Nietzsche's view of morality as being "a weapon of the weak to bring everyone to the same level" (cited in Solomon 2007, p. 36), then we would have to answer that question in the negative. Contrary to Nietzsche's unashamedly elitist perspective, however, many contemporary discourses addressing organisational failures seek to bring ethics and, in particular, moral emotions back into the argument. Serious cases of care abuse and neglect in the UK's National Health Service (NHS), the VW emission scandal, the decades-long cover-up of sexual abuse by respected institutions (e.g. the BBC and Catholic Church) and a wide range of routine banking malpractices which emerged before (and since) the 2008 crisis have all been linked to ethical failures and, more specifically, to an absence of moral emotions in 
individual and collective decision-making processes. ${ }^{1}$ For instance, a deficit of compassion is linked to organisations failing their duty of care towards constituents (Fotaki 2015; Frost et al. 2000; Rynes et al. 2012), while an inability of perpetrators to experience shame or guilt following oppressive acts of workplace bullying, humiliation and discrimination are seen as contributing to a wide range of organisational malfeasance (Walker and Jackson 2016). That inability goes straight to the heart of this special issue: why do ethical transgressions (such as those already mentioned) "occur with surprising regularity despite strong inhibitors and social norms that emanate from personal and public shame" (Murphy and Kiffin-Petersen 2016)?

But this concern illuminates only part of the bigger picture. These on-going occurrences also raise significant questions about each organisation's ability to accomplish its own mission goals, and beyond that, to contribute to the wider betterment of society. As we elaborate here, morality reflects a concern for others (beyond one's personal or class interests). Seen in this light, we ask what the role of moral emotions is vis-à-vis how we organise ourselves around a common purpose (Holt and den Hond 2013; Inglis $2015)$ if the very notion of a common purpose or a common good is increasingly being questioned ${ }^{2}$ ? Thus, it is imperative both to examine what factors influence ethical challenges, transgressions and failures and to explore how these

\footnotetext{
$\overline{1}$ To take only the NHS and VW as relevant examples here, we note that according to the Mid Staffordshire NHS Foundation Trust Public Inquiry Report of February 2013, tens of thousands of vulnerable and elderly care patients felt at risk from abuse and often go hungry and unwashed in terms of the former. The report concluded this was the "the worst crisis any district general hospital in the NHS can ever have known" (p. 47, taken from https://www.gov.uk/government/ uploads/system/uploads/attachment_data/file/279124/0947.pdf, accessed on 15th March 2016). In terms of VW, as reported in the Sueddeustche Zeitung on 8 November 2015, the engineers seemingly manipulated the software that measured the $\mathrm{CO}^{2}$ emotions because they were fearful of the then CEO, Martin Winterkorn. As a result of the emission scandal (e.g. catering for anticipated repair costs), the company reported recently its first net loss in 15 years as highlighted in the Financial Times (see (http://www.ft.com/cms/s/0/c4f464ec7d45-11e5-98fb-5a6d4728f74e.html\#axzz40EWYd2uS, accessed on 15th March 2016). Share prices also declined almost $35 \%$ by October 2015 since the US regulators revealed the cheating in September 2015. If this financial turmoil should lead to future redundancies, the VW scandal is likely to gain an unequivocal moral dimension.

${ }^{2}$ Examples provided previously (e.g. the NHS) emphasise that the principle of the 'common good' is undermined by organisational malpractice. However, threats to the principle of the common good can just as well be observed in political commentaries. Fred Inglis (2015) notes that current thinking (among academics) "is directed towards keeping faith with the morally local scale of common decency, while acknowledging...the steady corruption of public life and the disappearance from the language of our ruling class of any conception of the common good. When the prime minister writes... of Britain as a "bloated, high-taxing welfare-heavy nation", he speaks, as the very rich and powerful mostly do, in complete disregard of the obligations of the State towards all its members" (p. 44).
}

contraventions lead us astray from the 'moral endpoints' of our actions (Durkheim 1893/2014; Mill 1861/2001; Solomon 1993a). In consequence, the main purpose of this special issue is to deepen our understanding of the role of moral emotions in organisations as part of the wider discourses on organisational ethics and morality.

As a general approach, we present here some core arguments and perspectives in the field and then synthesise these with the articles constituting the corpus of this special issue, the reason being that an introduction to a special issue can accomplish more than present a summary of its articles (Brown et al. 2009; Lindebaum and Jordan 2014). Specifically, our introduction first defines moral emotions and examines their relation to ethical and unethical organisational behaviour. We then take our discussion to the realm of bureaucracy and organisation, and examine how moral emotions and ethical behaviour affect organisations both in terms of its processes and outcomes, including claims that organisations neutralise moral emotions and make individuals indifferent to the suffering of others. We consider the unique position of managers and leaders, as organisational agents, including the higher moral profile of leadership, at least through the eyes of followers, and consider how key organisational figures may embody - or fail to embody - a caring attitude towards those in their stewardship. We conclude by coming full circle to examine the argument that organisation and bureaucracy, far from being enemies of morality, can be its defenders-protecting individuals from nepotism, discrimination and even persecution. Following a review of our featured articles from geographically diverse regions and various work contexts, we also offer several avenues for future research beyond the insightful and thought-provoking ones offered in each article of this special issue.

\section{Moral Emotions and Morality}

Suddaby (2010) observes that "just as constructs are the building blocks of strong theory, clear and accurate terms are the fundament of strong constructs" (p. 347). Therefore, we define the constructs of central concern here, starting with emotion as "a response to a stimulus where individuals experience a feeling state and physiological changes, with downstream consequences" (Elfenbein 2007, p. 317). Emotions inform, as Zajonc (1980) reminds us, our value judgments that lead to approach or avoidance decisions and actions. More specifically, we draw upon Haidt's (2003) definition of moral emotions as emotions "that go beyond the direct interests of the self", meaning they are "linked to the interests or welfare either of society as a whole or at least of persons other than the judge or agent" (p. 853, italics added). This view of moral emotions 
is consistent with the broader term, morality, seen as an "interlocking sets of values, practices, institutions, and evolved psychological mechanisms that work together to suppress or regulate selfishness and make social life possible" (Haidt 2008, p. 70). Thus, whether directly or indirectly, moral emotions such as anger, regret, shame, guilt, embarrassment and even Schadenfreude (see Dasborough and Harvey 2016; Walker and Jackson 2016) entail some appraisal or perception of a situation linked to the interests of others, dictating specific courses of action.

This is a key consideration, since even a discrete emotion can be prompted by many different factors and may, correspondingly, engender multiple action tendencies. This holds true for sadness (Gray et al. 2011) and anger (Lindebaum and Gabriel 2015) to name only two basic emotions. For example, moral anger can be viewed as a specific type of anger, highlighting theoretical links among the appraisal of an event as morally unacceptable, the action tendency that follows from it and the intended outcome to put right a moral wrong. Thus, Lindebaum and Geddes (2015, p. 6) define moral anger as “(i) an aroused emotional state stemming from (ii) a primary appraisal of a moral standard violation that (iii) impacts others more than oneself and (iv) prompts corrective behavior intended to improve the social condition, even in the face of significant personal risk" (p. 6). In this way, moral anger over injustices or improprieties at work can provoke organisational members to confront an offending agent or approach those able to redress a problematic situation for the benefit of others (Geddes and Callister 2007; Geddes and Stickney 2011; Stickney and Geddes 2016).

A concern for others is viewed as necessary for the very existence of society (Durkheim 1893/2014; Mill 1861/ 2001; Solomon 1993a). From this vantage point and consistent with Haidt (2008), we embrace a social functional perspective, where morality and moral emotions ultimately suppress selfishness and promote caring, cooperative attitudes and behaviours. ${ }^{3}$ This view reflects a long tradition in sociology where:

It is impossible for men to live together and be in regular contact with one another without their acquiring some feeling for the totality which they constitute through having united together, without their becoming attached to it, concerning themselves with its interests and taking it into account in their behavior. And this attachment to something that transcends the individual, this subordination of the

\footnotetext{
3 Solomon (2007) offers the germane observation that "[we] tend to be selfish and act in [our] own self-interest (to the obvious detriment of others) only when [we] are taught or forced to do so, by an excessive emphasis on competition to the detriment of co-operation" (p. 29).
}

particular to the general interest, is the very wellspring of all moral activity (Durkheim 1893/2014, p. 18).

The concept of care (Fürsorge in German) plays a central part in sociology, including Heidegger's philosophy (Tomkins and Eatough 2014), and lies at the heart of Gilligan's (1982) pioneering work that established 'ethics of care' as a distinct field of both moral philosophy and moral psychology. In contrast to 'ethics of justice', ethics of care theorists argue for a different system of morality, one that does not rely on claims of universality, absolute judgments of right and wrong, and perfect virtues. Instead, they propose a practical morality that grows out of a recognition that every individual is embedded in complex webs of social relations, depending upon others for their survival and well-being, and capable of supporting others in their moments of need and helplessness. Moral emotions are essential in sustaining these networks and supporting the needs of others to whom we feel close and for whom we are prepared or expected to take responsibility. Caring is not a scripted performance or the manufactured smile of 'emotional labour' (Hochschild 1983), but involves a wide range of emotions, actions and concerns that grow out of emotional sensitivity and empathy towards the needs of those within our realm of influence (Gabriel 2008a).

\section{Moral Emotions and Ethical Organisation}

When looking at ethical behaviour and moral emotions from an organisational perspective, a number of intriguing issues arise. We approach organisation both as a process of maintaining or restoring a certain type of order, and also as a special type of social collectivity that places moral demands on its members distinct from those posed by one's family, community or nation. Organisation, as a phenomenon, describes a particular type of social order-one that can characterise the functioning of any social grouping, long-term or short-term, with accomplishing collective aims and purposes, while complying with wider social codes and values (Ahrne and Brunsson 2010). Nevertheless, most contemporary forms of organisation entail a degree of bureaucratic impersonality that impacts their members' moral compass. In the interesting case of the NHS's zero tolerance policy for "verbal abuse" towards its employees, care givers are charged with the responsibility of possibly withholding necessary medical attention, if their patient's (or patient family members') words or intensity exceed 'appropriate' levels. ${ }^{4}$ As Solomon (1993a) notes, our over-emphasis on rules and results can

\footnotetext{
${ }^{4}$ See, for example, this website: http://www.westpoint-gp.nhs.uk/ info.aspx?p=9 accessed on 14th of March 2016.
} 
undermine the nature of our ordinary moral judgments. In these circumstances, moral emotions can be blunted or muted so that the application of impersonal rules to accomplish organisational objectives takes precedence over social and ethical values and norms. This is the view of organisation sine ira et studio handed down to us by Max Weber and his successors, which Fineman (1993) describes as emotionally anorexic.

Emotions, including moral emotions, may be suppressed in an organisation, although they may be far from absent. In fact, many organisations commandeer employee emotions for their own ends, requisitioning emotional labour to achieve company objectives (Hochschild 1983; Lindebaum 2012). This instrumental and compensated deployment of emotion in organisations, however, can further exacerbate moral blindspots. Displaying prescribed emotions to defuse the anger of an irate customer or evict a tenant from his or her home, or fabricated emotions to ingratiate oneself to a superior are unlikely to enhance an organisation's moral climate. If anything, such actions debase the ability of moral emotions to govern and inhibit anti-social impulses. It is for these reasons that Bauman (1989), interpreting Nazi party barbarism, argued that bureaucratic ethics instil an unprecedented sense of indifference to the well-being and the suffering of other people and provide a moral amnesty for highly questionable practices that demonstrate 'following orders'. We learn from history that "the most terrible things_-war, genocide, and slavery_have resulted not from disobedience, but from obedience" (Zinn 1997/ 2009, italics added).

\section{Managers and Morality}

Although not a primary focus of our special issue, managers often emerge as central figures in discussions of workplace ethics and morality as a personification of the organisation itself, including its most unethical self. Consequently, some discussion of prominent organisational members is warranted, relative to morality, ethics and moral emotions. As holders of offices in formal hierarchies, acting in line with rules and regulations, and enforcing procedures and routines in an impersonal manner, managers in today's organisations can easily lose sight of ethical implications regarding their actions. They may develop moral blindspots prompted by bureaucracy and simply "doing their job". Disciplining a recalcitrant individual or dismissing a redundant employee reflect actions stripped of ethical dimensions and become mechanical applications of procedure. Jackall (1988/2010), who investigated in detail the morality of managers at work, concluded that most of them operate in an ethics-free zone of their own creation, where morality is reduced to compliance with legal and professional regulations and to public relations. He argued further that "the most salient aspect of morality as the managers themselves see it [is] how their values and ethics appear in the public eye" (p. 15).

The view of managers as essentially amoral agents of organisations whose very function is to convert ethical issues into technical ones is a centrepiece in the moral philosophy of Alastair MacIntyre (2007). The manager, he argued, "represents in his character the obliteration of the distinction between manipulative and nonmanipulative social relations... The manager treats ends as given, as outside his scope; his concern is with effectiveness in transforming raw materials into final products, unskilled labour into skilled labour, investment into profits" (p. 30, italics added). Management, according to this view, treats people as resources to be deployed for the end of efficient administration, free of moral considerations (see also Ghoshal 2005). Conveniently, this renders moral and political concerns invisible, turning them into issues of technical efficiency. Practicing managers seek to control people, information and other resources in the face of continuous change and uncertainty. To this end, virtually any concept or technique may be so marshalled.

MacIntyre (2007) regarded the manager as one of the defining characters of our age — an age of what he viewed as unprecedented moral confusion and ignorance. He argues that we have lost faith in our ability to make rational arguments about moral matters and base our judgments on purely emotional hunches and whims. A picture of an animal in pain will persuade us that animal experimentation is a bad thing; later, a picture of a child whose life depends on a drug tested on animals will persuade us to change our mind. This is what he referred to as 'emotivism', or 'the doctrine that all evaluative judgments and more specifically all moral judgments are nothing but expressions of preference, expressions of attitude or feeling, insofar as they are moral or evaluative in character" (pp. 11-12, emphasis in original). The manager as an archetype of this moral landscape is capable of speaking the language of morality to attain technical aims, such as funding for particular projects, but fails to grasp its true meaning.

In sharp contrast, other scholars have effectively challenged the view of managers as morally indifferent or ethically capricious. Watson's (1994) and Fineman's (1998) ethnographic studies suggest that at least some managers are neither moral illiterates nor immoral robots, but fallible and at times confused agents seeking to accommodate diverse demands, including ethical demands made upon them. Having shadowed managers in a UK telecommunications company for a whole year, Watson empathetically concluded that "in spite of the existence of pressures towards such a state of affairs identified by Jackall, I believe that the majority of managers I worked with at Ryland would be incapable of acting as amoral and 
unfeeling agents of remote financial interests" (1994: 210, emphasis added).

\section{Leaders and Morality}

The argument that managers' actions are predominantly instrumental and that efficiency often overshadows ethical concerns continues to enjoy considerable currency. Nevertheless, over the past 30 years, distinctions are regularly made between management and leadership in organisations, necessitating a separate, brief discussion here regarding "leaders" (Bass 1985; Burns 1978). While moral qualities of managers are viewed as secondary to their ability to run organisations efficiently, leaders, by contrast, are seen as organisations' moral agents-expected to display moral courage and rectitude, to lead by example, and to personify the moral climate of their organisation or of society at large (Ciulla et al. 2005). Nevertheless, moral wrongdoing by leaders may undermine the morality of an organisation and legitimise all kinds of infractions, as well as undermine the legitimacy of the leaders themselves. Thus, a lively debate is on-going as to whether leadership, in its very essence, embodies assumptions of goodness, integrity and virtue (Burns 1978; Ciulla 1998/2004; Ciulla and Forsyth 2011), or whether this is a wish-fulfilling illusion and leadership is essentially an amoral concept (Bass 1999; Kellerman 2004). This debate, whose earlier contributors include Plato, Machiavelli and Hobbes, remains inconclusive. What is clear, however, is that followers expect their leaders to behave ethically, whether the latter do so or not.

Leaders are expected to treat their subordinates with dignity and respect, acknowledging, if not always fulfilling, their followers' needs and aspirations. It is in this context that theories of servant (Greenleaf 1977) and caring leadership (Ciulla 2009; Gabriel 2015; Tomkins and Simpson 2015) developed, drawing sometimes on the emerging philosophy and psychology centering upon the ethics of care and compassion. The underlying concept of caring here is not a generalised attitude, as in "I care about the future of the planet" or "I care about the condition of prisons", but a direct emotional engagement with people for whom the leader feels directly responsible and whose well-being he/she sees as a priority.

Organisations, with their impersonal and bureaucratic attributes, are frequently seen as curtailing the ethic of care. Yet, the expectation that leaders should care for the wider good and not only for their personal enhancement or gratification is widely accepted. This has drawn leadership theories close to the study of emotions (Eisenbeiss and van Knippenberg 2015) and opens up the morality of leaders to a scrutiny of the emotions that identify, support and respond to it.

\section{Moral Emotions, (Un)ethical Actions and Morality} in Organisations

Previously, we argued that moral emotions provide preliminary and crucial support for ethical action. This means they often provide an instant appraisal of the ethical standing of prominent organisational members (i.e. managers and leaders), particular situations and/or colleagues' actions, indicating whether they are "good" or "bad". For example, moral anger has both informational (i.e. involving and attribution of blame) and energic (i.e. motivational) value, which jointly determine if, how, and by whom restorative action may be taken, while providing the impetus and motivation for undertaking such action (Lindebaum and Gabriel 2015). Symmetry often accompanies our determinations of good and bad organisational policies, practices and behaviour. When favourable assessments and subsequent emotions occur, organisations and their agents are seen as promoting justice, compassion and integrity in the work environment. When an individual or situation are negatively evaluated, however, moral emotions often involve an attribution of blame (towards the self or others-see Solomon 1993b; Walker and Jackson 2016).

Beyond this intuitive symmetry, however, are circumstances when profoundly moral emotions can lead to unethical behaviour and support anti-social actions. This is the position taken by Schwartz (1987), who argued that many organisations today, far from relying on the moral indifference of their members, seek to generate a zealotlike commitment in them, by fuelling their narcissism. As members of glamorous and powerful organisations, individuals can feel important and powerful, their lives being full of meaning. Without the organisation, they feel lost, deracinated and weak. Organisations encourage their members to identify with them to a maximum extent, thus creating relations of acute dependence. Many of their members become organisational acolytes (Hopfl 1992), working long hours and making many personal sacrifices in the interest of the organisation, on whose grandeur and success their own narcissism (and financial support) relies.

In this way, organisations can take over individuals' moral emotions, turning them into triggers for anti-social actions and unethical behaviours. An individual's guilt, argues Schwartz (1987), comes to be controlled by the employer. Instead of feeling guilty for committing illegal acts-such as concealing the truth, deceiving customers or harming the environment-individuals are liable to feel guilty for not protecting their organisation from external scrutiny, not working hard enough, or even not being ruthless enough in pursuit of their organisational duties.

There are further conditions under which moral emotions can create moral blindspots, and, as a result, promote 
immoral and misguided action. Studies on social movements show that 'injustice frames' are key to promoting protest, depending upon "the righteous anger that puts fire in the belly and iron in the soul" (Gamson 1992, p. 32). However, experimental studies show that hostility to authority preceded the development of such an injustice frame when individuals were exposed to transgressions by authoritative figures (Gamson et al. 1982). Therefore, anger, suspicion or other emotions may be induced even before blame is attributed-through more cognitive processes-to another individual or group, leading to misplaced and misdirected blame. Such distortions generate consequences where individuals "exaggerate the role of human actors, failing to understand broader structural constraints, and misdirect their anger at easy and inappropriate targets" (Gamson 1992, p. 33).

Thus, moral emotions by themselves offer no guarantee of ethical behaviour, an issue that comes to the fore in the behaviour of whistle-blowers, for instance. Are these individuals deeply ethical human beings who, appalled at organisational malpractices, decide to blow the whistle? Or are they ethically crippled individuals who, disenchanted with their employer or with life in general, decide to wreck what is valuable and important to others by tarnishing their organisation's image and contaminating its brand (Alford 2001; Gabriel 2008b)? Clearly, both scenarios are possible, which makes the relationship between moral emotion and ethical behaviour potentially problematic. Our moral impulse can sometimes lead us astray, for example, when we scapegoat an individual or a group, holding them responsible for our own failures or suffering, even when they have nothing to do with it.

Rousing their followers' passions in pursuit of opportunistic, selfish or downright immoral ends has long been the trademark of demagogues and rabble-rousers. There is ample evidence from political psychology confirming Schwartz's (1987) insight that moral emotions can, in the right circumstances, lead to highly immoral actions, especially when people act as members of a crowd. Crowds are, in general, known to have an unquestioned conviction of their own morality and the immorality of their adversaries (Freud 1921/1985; Le Bon 1885/1960), a phenomena replicated in smaller settings under conditions of groupthink (Janis 1982). A cast iron conviction that one's cause is right while one's adversary is wrong offers no guarantee against skulduggery. Consequently, in certain circumstances, it could be argued that far from an enemy of morality, organisation can be viewed as its defender. Minimally, an organisation can serve as the defender of a particular type of morality, one that emphasises equality, transparency and proper allegiance to agreed procedures and norms. This applies in as much as the organisation seeks to tame individuals' and groups' propensities to act impulsively and justify biased or blinded forms of action by reinforcing consistent standards of treatment.

This is the forceful position adopted by Paul du Gay (2000) in his book, In Praise of Bureaucracy, who argues that, far from being the enemy of morality, bureaucracy offers a defence against charismatic and pseudo-charismatic leaders who threaten morality by stirring moral emotions in pursuit of devious ends. Offering a radically different interpretation of the Nazi holocaust from Bauman (1989), du Gay proposes that it was fanatical allegiance to the Führer rather than an impersonal allegiance to a bureau (in the Weberian tradition) that sustained a project of planning and launching wars of aggression, perpetrating mass extermination and other crimes against humanity. Du Gay's view that genocide represents an instance of exaggerated zeal in applying a perverse morality is quite consistent with the view of several contemporary historians (Allen 2002; Bauer 2001; Finkelstein 2000; Friedländer 1997; Goldhagen 1996), who have moved away from the traditional view of the perpetrators of Nazi crimes as dull bureaucrats blindly pursuing their 'duties' (Arendt 1963; Bauman 1989; Hilberg 1985) and towards the view of them as dedicated and even moralistic enthusiasts of a cause (for an overview, see Stokes and Gabriel 2010).

Thus, we come full circle with our introductory essay. From organisation as a neutraliser of moral emotions and a disabler of individuals' moral impulse to organisation as a neutraliser of untamed passions and a guardian against power abuses by individuals or a crowd mentality that can always find good, moral reasons for doing the wrong thing. In this special issue, contributing authors make compelling arguments addressing these and other concerns highlighted in our Call for Papers. We integrated these perspectives to thematically organise our special issue.

\section{Moral Emotions, Ethical Behaviour and Social Pressure}

Marie Dasborough and Paul Harvey (2016) contribute one of the first empirical studies on Schadenfreude with a workplace focus. Seemingly counterintuitive at first, the authors argue that Schadenfreude, or pleasure derived from another's misfortune, is a moral emotion, given its disinterred elicitors (i.e. the self is not directly affected by it) and pro-social action tendencies-both hallmarks of moral emotions. Dasborough and Harvey agree that Schadenfreude initially appears to have no pro-social action tendency. However, once the lens of social functional emotions is applied, they argue that Schadenfreude reflects pro-social behaviours since shared emotions serve adaptive functions in the coordination and maintenance of relationships among individuals, collectives and cultures. 
Emotions promote social learning and deter (e.g. in cases of norm or value violations) or incentivise other individuals' social behaviour. Schadenfreude sends a negative signal to the observed person (e.g. a person committing ethical transgressions) that such behaviour is not tolerated. The two scenario, empirical studies by Dasborough and Harvey shed light on relevant boundary conditions. Specifically, in study 1, those experiencing Schadenfreude intended to share that feeling with others, particularly if they felt the misfortune of the unethical CEOs (scenarios based upon factual news stories) was deserved. In study 2 , these authors extended their findings by adding targets of Schadenfreude with different status (i.e. CEO vs. employee). They found participants willing to share Schadenfreude regarding targets of high status rather than low status, especially when the perceived severity of the target's misconduct was low. However, the status effect vanished with higher degrees of target transgression. In our view, their studies significantly extend the social functional account of Schadenfreude, insofar as its social sharing conveys normative signals to others about behaviour at work considered unethical or immoral. Thus, Schadenfreude can function to deter potential moral transgressors.

Jagannathan and Rai (2016) examine in detail the ethical issues raised by police killings of suspected terrorists in India, euphemistically referred to as 'police encounters'. Against a background of ethnic tensions and terrorist outrage, the authors examine the roles of anger as an emotion that both supports and justifies extra-judicial killings, but also opposes and resists such justifications. The article draws on one of the author's first-hand experience as a police officer and the testimony of another officer who successfully tracked terrorist suspects, but refused to participate in extra-judicial activities. By juxtaposing this officer's stories to those of other participants (including journalists and fellow officers), the authors address one of the oldest and most enduring issues in moral philosophycircumstances under which illegal means may be used for an ostensibly greater good. They demonstrate how difficult it is in conditions of crisis for moral anger to prevail against "blind anger" fuelled by anxiety and an inability to acknowledge grief and engage in collective mourning. Indirectly, the article examines how courage in the face of formidable state power is sustained by the enduring moral qualities of anger, when rooted in opposition to violence, no matter the perpetrator. More directly, this piece suggests that while blind anger is hostile to discussion and reasoning, moral anger is fundamentally dialogical—seeking to establish coalitions of dissent to violence. Deprived of time and space for dialogue and reasoning, however, moral anger can become ineffectual and yield to other, more primitive impulses.

\section{Moral Emotions and Their Consequences Within/ Across Levels of Analysis}

Walker and Jackson (2016) provide one of the first comprehensive reviews detailing the link between corporate psychopathy and a range of moral emotions. This review reflects a greater focus on psychopathy as an individual difference variable (as opposed to structural influences) in the corporate context. As the authors note, corporate psychopaths are "subclinical psychopaths within an organisational setting" that research suggests may prove advantageous as they pursue individual rewards that allow for significant advancement. But once they are at the top (or presumably en route to it), they can wreak havocovert and latent - in the organisation, from interpersonal manipulations to large-scale fraud. After summarising work examining the range of moral emotions, Walker and Jackson review studies on psychopathy in relation to them. These studies are organised around their functional quality (i.e. is the signal positive or negative?) and the target of the moral emotion (i.e. self-directed vs. other-directed). A fundamental contribution of this review is to advance our understanding of how moral emotions relate to psychopathy. More precisely, the review suggests that psychopaths are high in moral emotions associated with other-directed negative signals (e.g. anger, contempt, scorn and envy). For instance, the authors detail the example of a corporate psychopath who displayed rage when his secretary, in his view, disrespected him. He subsequently demanded of his superior that she be fired. Further to this, the authors show that psychopaths tend to be low in self-directed negative signals (e.g. guilt, regret, remorse, or shame). In other words, psychopaths seem less likely to experience shame due to their low concern for social conventions and others. Psychopaths are also low in other-directed positive signals (e.g. awe or admiration), since this runs contrary to their self-interest. The review did not ascertain any empirical articles concerning psychopathy and self-directed positive signals (as in the case of pride). However, indirect evidence is offered suggesting corporate psychopaths can potentially use pride as a type of 'macho' response to threats that help restore their pride. A key practical implication is the need to be sensitive to psychopaths who frequently signal others to change their behaviour, but rarely change their own. Detecting this pattern before promoting such individuals to more senior positions may help prevent major crisis in the organisation.

Murphy and Kiffin-Petersen (2016) significantly advance our understanding of workplace shame- - both in terms of dispositional and organisational influencesacross levels of analysis. They provide a comprehensive review of the topic and offer a conceptual model containing 
a set of testable propositions. The authors question why unethical behaviour at work and society occurs "with surprising regularity despite strong inhibitors and social norms that emanate from personal and public shame". In response to this, they extend previous works and incorporate dual pathways to theorise how felt and anticipated shame shapes and affects ethical behaviour. While shame qualifies as a moral emotion (Tangney et al. 2007), they argue it can be more difficult for individuals to learn from moral transgressions (even minor ones) in order to inform their future behaviour. This is due to attributing failure to the 'global self', coupled with the infrequency and intensity of feeling shame. Consequently, the authors propose that a potentially more important function of shame is invoking an individual's moral judgment, namely, illuminating their evaluation of right and wrong. Their review also asserts that shame's impact on unethical workplace behaviour is best comprehended by combining multiple levels of analysis. This, the authors underline, has been frequently overlooked in the literature of shame at work. Finally, Murphy and Kiffin-Petersen offer further explanations as to why shame sometimes leads to adaptive reparative behaviour, while at other times, it induces further transgressions. Overall, this piece will serve as a useful roadmap to inform future research on shame in organisations across levels of analysis.

Harvey, Martinko and Borkowski's article (2016) examines how causal perceptions and moral emotions (i.e. anger, shame and guilt) help justify deviant workplace behaviour. Using Attribution Theory and Affective Events Theory to frame this research, the authors argue that causal attributions regarding negative workplace events generate unique emotions which can, in turn, stimulate deviant behaviours. For instance, following a negative workplace event, individuals may attribute culpability to the employing organisationseen as a relatively stable, controllable factor. This generates anger and resentment that may lead organisational members to feel justified in subsequent deviant action (cf. also studies on social movements mentioned earlier-Gamson 1992). Relatedly, when undesirable, affective workplace events are attributed to stable and personally uncontrollable factors, shame results-with unique effects on deviance. The same proves true when unfavourable work events are attributed to stable (or unstable), personally controllable factors. Guilt that results, for example, may inhibit or promote deviance. Limited empirical assessment examining these emotionmediated relationships offers an empirical gap this two-study project helps address. Although their hypotheses initially argue all three emotions could promote "justified" deviant behaviour, study results show a more complicated relationship among emotions and deviance. Sample characteristics (student versus physician), context (e.g. socialisation, ethical standards and life experience) and the blending of moral emotions appear to impact the strength and nature of the 'attribution-emotion-behaviour' (Weiner 1985) relationships. These studies and their conclusions offer a strong foundation from which future research can untangle (or perhaps co-mingle) thought process and emotional reactions arising from frustrating organisational encounters in an effort to help minimise damaging workplace deviance.

\section{Psychoanalytic Perspectives on the Management of Moral Emotions}

The topic of moral blindness returns in this article by De Klerk (2016), who uses a psychoanalytic perspective to investigate the unconscious defence mechanisms that frequently result in people with high moral standards engaging in morally questionable behaviours. Emotions, including moral emotions, argues De Klerk, can be unconscious and exercise a strong influence on people's behaviour without them being aware of their own motives. An unconscious conflict between moral impulses and potentially anti-social emotions such as greed, aggression or envy can result in anxiety. This nervous response is then fended off through a variety of defence mechanisms, like projection, denial, repressions, rationalisation or idealisation. All these, in turn, lead to various distortions in people's sense of reality or perspective, including complete 'blindness' in the face of glaring moral wrongdoing. De Klerk identifies four fundamental modes of dealing with unconscious emotions including emotion avoidance, regulation to mitigate emotion, failure to regulate emotion and regulation to shield emotion-each contributing in its own way to moral blindness. Recognising the role of unconscious conflicts and impulses, De Klerk moves beyond the view of moral blindness as ignorance and prompts us to think of it as a motivated psychological process with unpredictable outcomes.

\section{Virtue and Moral Emotions}

Karakas et al. (2016) develop a multi-dimensional framework of moral imagination based on interviews with executives in Turkish organisations. To stimulate imaginative thinking, they identify nine sets of virtues, each corresponding to a particular root metaphor. The virtues are integrity, affection, diligence, inspiration, wisdom, trust, gratefulness, justice and harmony, while corresponding metaphors include a well-oiled system, intimate family, talent fest, art workshop, human brain, closely knit community, play-space, court room and round table. The primary data demonstrate a remarkable degree of moral sophistication on the part of managers who participated in 
the study, including the sharp realisation of knotty problems that arise when virtues find themselves in conflict. In addition to developing the theory of moral imagination, the article shows how moral emotions underpin several core virtues and, in the case of emotions like love, joy, hope and compassion, constitute these virtues. Importantly, the article offers a compelling account of a synthesis between an Islamic ethic of hard work and spiritual values with a neoliberal ethic of innovation and entrepreneurship which aims to harmonise individual well-being with a wider concern for social well-being and justice.

\section{Moral Emotions and Action Tendencies}

Using interview and diary data, Linehan and O'Brien (2016) seek to better understand recurring emotional and ethical challenges faced by HR professionals. Their article illuminates complicated, moral dilemmas these individuals confront daily as they attempt to address the needs of multiple organisational 'others', including individual (and collective) employees and management. When faced, literally, with an employee requiring their attention, HR professionals often feel conflicted determining what is 'the right thing to do'. Moral emotions arising from a sincere concern for another's well-being collide with motivations to maintain professional detachment when conducting roleprescribed responsibilities. Thus, emotion display rules often serve to override or neutralise the moral impulses of those tasked with supporting employee growth, engagement and general welfare. This study highlights the relational and fluid nature of ethical awareness and decisionmaking in HR practice. Linehan and O'Brien map the processes HR professionals use as they enact their role and rationalise their actions while simultaneously shifting alliances between proximal and distal 'others'. These practices include determining employee culpability, significance of consequences and rationalising emotional appeals during interactions. For HR professionals, moral emotions emerge as a "tell-tale sign" that ethical challenges will confront them as they decide on-and live with - a chosen course of action. This research clearly articulates the often daily ethical struggles of HR practitioners while providing conceptual insights into critical outcome variables including employee burnout, commitment and retention.

Finally, Wilner et al. (2016) examine what happens when the 'unmanaged organisation' (Gabriel 1995) moves beyond its physical confines and into social media. Internet and social media use especially have created new avenues for expressing dissent. These omnipresent forums allow employees to publicise organisational malpractices and voice opposition to their employing organisation and its brand, products and promoted practices. The internet opens up new opportunities for parrhesia or 'speaking truth to power'. At the same time, however, it affords every fanatic, malcontent and narcissist opportunities to express unchallenged opinions and views. Under the protection of anonymity, social media can become a space for denunciations characteristic of terror regimes. The authors analyse certain instances when images and texts were published online, escaping organisational controls. These often emerge in specialist sites that encourage participants to voice criticisms of their employer. Out of fifty cases considered in this study, only three came close to Foucault's (2001) view of parrhesia as 'fearless speech'. The analysis of online resistance and dissent enabled these authors to identify three core ambiguities: ambiguity between private and public spheres, ambiguity between spontaneous and performed manifestations and ambiguity between the distribution and control of power. Each of these ambiguities can enhance the scope and effectiveness of online dissent; nevertheless, they can also neutralise, eviscerate or discredit it. As a democratised space for self-expression, the internet and social media emerge as highly contested terrains where different interests and claims compete for ascendancy and where successes and failure can be shortlived. Yet, concurring with Mestrovic (1996), these authors express deep unease regarding the venting of emotions in social media, questioning whether emotions behind the abundant outpourings of sentiment on the web, can maintain their moral compass and provide a firm guide to action.

\section{Beyond this Special Issue-Future Research}

In this section, we revisit and draw out potential explanations as to why serious ethical transgressions continue to emerge. In our view, seeking to explain what factors or constructs may influence each other is a necessary but insufficient condition to explain why or how these occur a priori. As some contributions in this special issue suggest, it may be the inability to experience moral emotions, such as shame or guilt, that foster unethical or immoral actions at work (Murphy and Kiffin-Petersen 2016; Walker and Jackson 2016). In this respect, we recognise-with clear caveats-two potential avenues for future research to explain why or how, for instance, individuals possess or develop an inability to experience moral emotions. At the individual level, the first path lies in the emerging literature on the neuroscience of ethical decision-making. These studies are interested in, for instance, better understanding the neural mechanisms that influence ethical decisionmaking in relation to a range of relevant issues, such as trust, altruism, fairness, revenge, social punishment, social norm conformity, social learning and competition (Rilling 
and Sanfey 2011). Nevertheless, scholars must consider the limitations of putatively more objective and rigorous neuroscientific data prior to attempting to build new theory (Lindebaum 2016; Niven and Boorman 2016). Further, scholars should recognise that any such exploration might raise ethical questions in itself (Lindebaum and Raftopoulou 2015), and that there are unresolved theoretical/ philosophical challenges in bridging the biological and social domains (Lindebaum and Zundel 2013).

Second, we propose a fresh look at more structural considerations in better understanding the inability or reduced likelihood to experience moral emotions or, equally important, the presence of amoral emotions (e.g. greed, envy, jealousy, etc.) and their origins and articulation in organisational settings. This appears important, as both the presence of amoral emotions and the absence of moral ones have bearing upon our ability to regulate selfishness and make social life possible (Haidt 2008). In particular, we propose revisiting Durkheim's (1893/2014) idea on the division of labour, which, if orchestrated appropriately, need not threaten the moral cohesion of society. But, as Durkheim cautions, if the division of labour is excessively pushed, individuals risk becoming isolated as a result of the specialised task, to the point that this separation becomes "a source of disintegration" (p. 280) for both the individual and society. Crucially, he adds that individuals "no longer [will be] aware of the collaborators who work at [their] side on the same task... [they] even no longer [have] any idea of what that common task comprises" (p. 280). Durkheim used the term 'anomie', meaning a lack of moral regulation, to describe the 'pathological' consequences of an overly specialised division of labour. We suggest that anomie may prove a fruitful starting point to better understand the emergence and articulation of amoral emotions-as indicated before-in organisational settings and society. Consistent with our introductory reflections, it is noteworthy that Durkheim's writings in the late 19th century anticipated that the notion of the 'common task' may be threatened in the future. What is the consequence of this in times of increasing social divisions, inequality and even terrorism?

Finally, probing the morality of leaders and the influence of emotions in this continues to be a vitally important line of inquiry. Moral emotions play a dominant role in public debates as manifested by continuous slurs and insults being traded between candidates in the current American presidential primaries. These entail attempts to shame opponents for different aspects of their past record, attempts that easily backfire by calling into question the ethical judgement of the one launching the moral invective. Future research may take a closer look at the mere appearance of leader morality and the risks associated with seeking to occupy a moral high ground by questionable means.

\section{Conclusion}

The articles in this special issue responded in insightful and provocative ways to our goal of deepening the understanding of moral emotions' roles in organisations as part of wider discourses on organisational ethics and morality. Using a multitude of theoretical angles and methods, they significantly advance our theoretical and practical insights on the nexus among emotions, ethics and the world of organisations. We hope that researchers and practitioners will find some inspiration in this collection of articles to improve our theorising and approach to organisational practice around issues of moral emotions and ethical behaviour.

Acknowledgments We extend our heartfelt gratitude to all authors who considered our special issue as potential outlet for their work, although only some articles survived the review process. A very special 'thank you' goes to the excellent and reliable reviewers, who supported us along the way. We recognise that their reviews-delivered in a timely fashion-were instrumental in completing this special issue.

Funding This study has not received any funding.

\section{Compliance with Ethical Standards}

Conflict of interest All authors declare that they have no conflict of interest.

Ethical Approval This article does not contain any studies with human participants performed by any of the authors.

\section{References}

Ahrne, G., \& Brunsson, N. (2010). Organization outside organizations: the significance of partial organization. Organization. doi:10.1177/1350508410376256.

Alford, C. F. (2001). Whistleblowers: broken lives and organizational power. Ithaca, NY: Cornell University Press.

Allen, M. T. (2002). The business of genocide: The SS, slave labor, and the concentration camps. Chapel Hill, NC: University of North Carolina Press.

Arendt, H. (1963). Eichmann in Jerusalem: A report on the banality of evil. New York: Viking Press.

Bass, B. M. (1985). Leadership and performance beyond expectations. New York: Free Press.

Bass, B. M. (1999). Two decades of research and development in transformational leadership. European Journal of Work and Organizational Psychology, 8(1), 9-32.

Bauer, Y. (2001). Rethinking the Holocaust. New Haven: Yale University Press.

Bauman, Z. (1989). Modernity and the Holocaust. Ithaca, NY: Cornell University Press.

Brown, A. D., Gabriel, Y., \& Gherardi, S. (2009). Storytelling and change: An unfolding story. Organization 16(3), 323-333. doi: $10.1177 / 1350508409102298$.

Burns, J. (1978). Leadership. New York: Harper \& Row.

Ciulla, J. B. (Ed.) (1998/2004). Ethics, the heart of leadership. Westport, CT: Praeger. 
Ciulla, J. B. (2009). Leadership and the ethics of care. Journal of Business Ethics 88(1), 3-4. doi:10.1007/s10551-009-0105-1.

Ciulla, J. B., \& Forsyth, D. R. (2011). Leadership ethics. In A. Bryman, D. Collinson, K. Grint, B. Jackson, \& M. Uhl-Bien (Eds.), The SAGE handbook of leadership (pp. 229-241). London: Sage.

Ciulla, J. B., Price, T. L., \& Murphy, S. E. (Eds.). (2005). The quest for moral leaders: Essays on leadership ethics. Northhampton, MA: Edward Elgar.

Dasborough, M., \& Harvey, P. (2016). Schadenfreude: The (not so) Secret Joy of Another's Misfortune. Journal of Business Ethics. doi:10.1007/s10551-016-3060-7.

de Klerk, J. J. (2016). Nobody is as blind as those who cannot bear to see: Psychoanalytic perspectives on the management of emotions and moral blindness. Journal of Business Ethics. doi:10.1007/ s10551-016-3114-x.

du Gay, P. (2000). Praise of bureaucracy. London: Sage.

Durkheim, E. (1893/2014). The division of labor in society. New York: Free Press.

Eisenbeiss, S. A., \& van Knippenberg, D. (2015). On ethical leadership impact: The role of follower mindfulness and moral emotions. Journal of Organizational Behavior 36(2), 182-195. doi:10.1002/job.1968.

Elfenbein, H. A. (2007). Emotion in organizations: A review and theoretical integration. The Academy of Management Annals 1(1), 315-386. doi:10.1080/078559812.

Fineman, S. (Ed.). (1993). Emotion in organizations. London: Sage.

Fineman, S. (1998). Street-level bureaucrats and the social construction of environmental control. Organization Studies, 19(6), 953-974.

Finkelstein, N. G. (2000). The Holocaust industry: Reflections on the exploitation of Jewish suffering. London: Verso.

Fotaki, M. (2015). Why and how is compassion necessary to provide good quality healthcare? International Journal of Health Policy and Management, 4(4), 199-201.

Foucault, M., \& Pearson, J. (2001). Fearless speech. Los Angeles, Ca.: Semiotext(e): Distributed by MIT Press.

Freud, S. (1921/1985). Group psychology and the analysis of the ego Civilization, Society and Religion (Vol. 12, pp. 91-178). Harmondsworth: Pelican Freud Library.

Friedländer, S. (1997). Nazi Germany and the Jews: The years of persecution 1933-1939 (1st ed.). New York: HarperCollins.

Frost, P. J., Dutton, J. E., Worline, M. C., \& Wilson, A. (2000). Narratives of compassion in organizations. In S. Fineman (Ed.), Emotion in organizations (2nd ed., pp. 25-45). London: Sage.

Gabriel, Y. (1995). The unmanaged organization: Stories, fantasies and subjectivity. Organization Studies, 16(3), 477-501.

Gabriel, Y. (2008a). Latte capitalism and late capitalism: Reflections on fantasy and care as part of the service triangle. In M. Korczynski \& C. MacDonald (Eds.), Service work: Critical perspectives (pp. 175-190). London: Routledge.

Gabriel, Y. (2008b). Spectacles of resistance and resistance of spectacles. Management Communication Quarterly, 21(3), $310-327$.

Gabriel, Y. (2015). The caring leader-What followers expect of their leaders and why? Leadership 11(3), 316-334. doi:10.1177/ 1742715014532482.

Gamson, W. A. (1992). Talking politics. Cambridge, UK: Cambridge University Press.

Gamson, W. A., Fireman, B., \& Rytina, S. (1982). Encounters with unjust authority. Homewood, IL: Dorsey.

Geddes, D., \& Callister, R. R. (2007). Crossing the line(s): A dual threshold model of anger in organizations. Academy of Management Review, 32(3), 721-746.

Geddes, D., \& Stickney, L. T. (2011). The trouble with sanctions: Organizational responses to deviant anger displays at work.
Human Relations 64(2), 201-230. doi:10.1177/ 0018726710375482.

Ghoshal, S. (2005). Bad management theories are destroying good management practices. Academy of Management Learning and Education, 4(1), 75-91.

Gilligan, C. (1982). In a different voice: Psychological theory and women's development. Cambridge, Mass.: Harvard University Press.

Goldhagen, D. J. (1996). Hitler's willing executioners: Ordinary Germans and the Holocaust (1st ed.). New York: Knopf.

Gray, H. M., Ishii, K., \& Ambady, N. (2011). Misery loves company: When sadness increases the desire for social connectedness. Personality and Social Psychology Bulletin 37(11), 1438-1448. doi:10.1177/0146167211420167.

Greenleaf, R. K. (1977). Servant leadership : A journey into the nature of legitimate power and greatness. New York: Paulist Press.

Haidt, J. (2003). The moral emotions. In R. J. Davidson, K. R. Scherer, \& H. H. Goldsmith (Eds.), Handbook of affective sciences (pp. 852-870). Oxford: Oxford University Press.

Haidt, J. (2008). Morality. Perspectives on Psychological Science 3(1), 65-72. doi:10.1111/j.1745-6916.2008.00063.x.

Harvey, P., Martinko, M. J., \& Borkowski, N. (2016). Justifying deviant behavior: The role of attributions and moral emotions. Journal of Business Ethics. doi:10.1007/s10551-016-3046-5.

Hilberg, R. (1985). The destruction of the European Jews (Rev. and definitive ed.). New York: Holmes \& Meier.

Hochschild, A. R. (1983). The managed heart: The commercialization of human feeling. Berkely, CA: University of California Press.

Holt, R., \& den Hond, F. (2013). Sapere aude. Organization Studies, 34(11), 1587-1600.

Hopfl, H. (1992). The making of the corporate acolyte: some thoughts on charismatic leadership and the reality of organizational commitment. Journal of Management Studies 29(1), 23-33. doi:10.1111/j.1467-6486.1992.tb00650.x.

Inglis, F. (2015). Thoughts unbecoming. Times Higher Education, pp. 44-47.

Jackall, R. (1988/2010). Mazes: The world of corporate managers. New York: Oxford University Press.

Jagannathan, S., \& Rai, R. (2016). Organizational wrongs, moral anger and the temporality of crisis. Journal of Business Ethics. doi:10.1007/s10551-016-3153-3.

Janis, I. L. (1982). Groupthink: psychological studies of policy decisions and fiascoes (2nd ed.). Boston: Houghton Mifflin.

Karakas, F., Sarigollu, E., \& Uygur, S. (2016). Exploring the diversity of virtues through the lens of moral imagination: A qualitative inquiry into organizational virtues in the Turkish context. Journal of Business Ethics. doi:10.1007/s10551-016-3150-6.

Kellerman, B. (2004). Leadership warts and all. Harvard Business Review, 82(1), 40-45.

Le Bon, G. (1885/1960). The crowd: A study of the popular mind. New York: The Viking Press.

Lindebaum, D. (2012). I Rebel-Therefore we exist: Emotional standardization in organizations and the emotionally intelligent individual. Journal of Management Inquiry 21(3), 262-277. doi:10.1177/1056492611430125.

Lindebaum, D. (2016). Critical essay: Building new management theories on sound data?. The case of neuroscience. Human Relations 69(3), 537-550. doi:10.1177/0018726715599831.

Lindebaum, D., \& Gabriel, Y. (2015). Anger and organization studies-From social disorder to moral order. Organization Studies. http://oss.sagepub.com/content/early/2016/04/13/01708 40616640848.full.

Lindebaum, D., \& Geddes, D. (2015). The place and role of (moral) anger in organizational behavior studies. Journal of Organizational Behavior. doi:10.1002/job.2065. 
Lindebaum, D., \& Jordan, J. P. (2014). When it can be good to feel bad and bad to feel good: Exploring asymmetries in workplace emotional outcomes. Human Relations, 67(9), 1037-1050.

Lindebaum, D., \& Raftopoulou, C. E. (2015). What would John Stuart Mill say? A utilitarian perspective on contemporary neuroscience debates in leadership. Journal of Business Ethics.

Lindebaum, D., \& Zundel, M. (2013). Not quite a revolution: Scrutinizing organizational neuroscience in leadership studies. Human Relations 66(6), 857-877. doi:10.1177/0018726 713482151.

Linehan, C., \& O'Brien, E. (2016). From tell-tale signs to irreconcilable struggles: The value of emotion in exploring the ethical dilemmas of human resource professionals. Journal of Business Ethics. doi:10.1007/s10551-016-3040-y.

Macintyre, A. (2007). After virtue. Notre Dame, IN: University of Notre Dame.

Mestrovic, S. (1996). Postemotional society. London: Sage.

Mill, J. S. (1861/2001). Utilitarianism. London: Electric Book Co.

Murphy, S. A., \& Kiffin-Petersen, S. (2016). The exposed self: A multilevel model of shame and ethical behavior. Journal of Business Ethics. doi:10.1007/s10551-016-3185-8.

Niven, K., \& Boorman, L. (2016). Assumptions beyond the science: Encouraging cautious conclusions about functional magnetic resonance imaging research on organizational behavior. Journal of Organizational Behavior. doi:10.1002/job.2097.

Rilling, J. K., \& Sanfey, A. G. (2011). The neuroscience of social decision-making. Annual Review of Psychology 62(1), 23-48. doi:10.1146/annurev.psych.121208.131647.

Rynes, S. L., Bartunek, J. M., Dutton, J. E., \& Margolis, J. D. (2012). Care and compassion through an organizational lens: Opening up new possibilities. Academy of Management Review 37(4), 503-523. doi:10.5465/amr.2012.0124.

Schwartz, H. S. (1987). Anti-social actions of committed organizational participants: An existential psychoanalytic perspective. Organization Studies, 8(4), 327-340.

Solomon, R. (1993a). Ethics: A short Introduction. Dubuque, IA: Brown \& Benchmark.
Solomon, R. (1993b). The passions: Emotions and the meaning of life. Indianapolis: Hackett Publishing Company.

Solomon, R. (2007). Introduction to ethics. In W. C. Zimmerli, K. Richter, \& M. Holzinger (Eds.), Corporate ethics and corporate governance (pp. 11-36). Heidelberg: Springer.

Stickney, L. T., \& Geddes, D. (2016). More than just "Blowing off Steam": The roles of anger and advocacy in promoting positive outcomes at work. Negotiation and Conflict Management Research 9(2), 141-157. doi:10.1111/ncmr.12071.

Stokes, P., \& Gabriel, Y. (2010). Engaging with genocide: The challenge for organization and management studies. Organization 17(4), 461-480. doi:10.1177/1350508409353198.

Suddaby, R. (2010). Editor's comments: Construct clarity in theories of management and organization. Academy of Management Review, 35(3), 346-357.

Tangney, J. P., et al. (2007). Moral emotions and moral behavior. Annual Review of Psychology 58, 345-372.

Tomkins, L., \& Eatough, V. (2014). Stop 'helping' me! Identity, recognition and agency in the nexus of work and care. Organization 21(1), 3-21. doi:10.1177/1350508412461293.

Tomkins, L., \& Simpson, P. (2015). Caring leadership: A heideggerian perspective. Organization Studies 36(8), 1013-1031. doi:10. $1177 / 0170840615580008$.

Walker, B. R., \& Jackson, C. J. (2016). Moral emotions and corporate psychopathy: A review. Journal of Business Ethics. doi:10.1007/ s10551-016-3038-5.

Watson, T. J. (1994). In search of management: Culture, chaos and control in managerial work. London: Routledge.

Wilner, A., Christopoulos, T. P., \& Alves, M. A. (2016). The online unmanaged organization: control and resistance in a space with blurred boundaries. Journal of Business Ethics. doi:10.1007/ s10551-016-3184-9.

Zajonc, R. B. (1980). Feeling and thinking: Preferences need no inferences. American Psychologist 35(2), 151-175. doi:10.1037/ 0003-066x.35.2.151.

Zinn, H. (1997/2009). The Zinn reader: Writings on disobedience and democracy. New York: Seven Stories Press. 